\title{
Oxidative and Glycogenolytic Capacities within the Developing Chick Heart
}

\author{
ROBERTO ROMANO, ANNE-CATHERINE ROCHAT, PAVEL KUCERA, \\ YVES DE RIBAUPIERRE, AND ERIC RADDATZ
}

Institute of Physiology, Faculty of Medicine, University of Lausanne, CH-1005 Lausanne, Switzerland

\begin{tabular}{|c|c|}
\hline \multicolumn{2}{|c|}{ ABSTRACT } \\
\hline $\begin{array}{l}\text { Cardiac morphogenesis and function are known to depend on } \\
\text { both aerobic and anaerobic energy-producing pathways. How- } \\
\text { ever, the relative contribution of mitochondrial oxidation and } \\
\text { glycogenolysis, as well as the determining factors of oxygen } \\
\text { demand in the distinct chambers of the embryonic heart, remains } \\
\text { to be investigated. Spontaneously beating hearts isolated from } \\
\text { stage } 11,20 \text {, and } 24 \mathrm{HH} \text { chick embryos were maintained in vitro } \\
\text { under controlled metabolic conditions. } \mathrm{O}_{2} \text { uptake and glycogen- } \\
\text { olytic rate were determined in atrium, ventricle, and conotruncus } \\
\text { in the absence or presence of glucose. Oxidative capacity ranged } \\
\text { from } 0.2 \text { to } 0.5 \text { nmol } \mathrm{O}_{2} /(\mathrm{h} \cdot \mu \mathrm{g} \text { protein), did not depend on } \\
\text { exogenous glucose, and was the highest in atria at stage } 20 \mathrm{HH} \text {. } \\
\text { However, the highest reserves of oxidative capacity, assessed by } \\
\text { mitochondrial uncoupling, were found at the youngest stage and } \\
\text { in conotruncus, representing } 75 \text { to } 130 \% \text { of the control values. At } \\
\text { stage } 24 \mathrm{HH} \text {, glycogenolysis in glucose-free medium was } 0.22 \text {, } \\
0.17 \text {, and } 0.04 \text { nmol glucose } \mathrm{U}(\mathrm{h} \cdot \mu \mathrm{g} \text { protein) in atrium, ventricle, } \\
\text { and conotruncus, respectively. Mechanical loading of the ventri- } \\
\text { cle increased its oxidative capacity by } 62 \% \text { without altering } \\
\text { glycogenolysis or lactate production. Blockade of glycolysis by }\end{array}$ & $\begin{array}{l}\text { iodoacetate suppressed lactate production but modified neither } \\
\mathrm{O}_{2} \text { nor glycogen consumption in substrate-free medium. These } \\
\text { findings indicate that atrium is the cardiac chamber that best } \\
\text { utilizes its oxidative and glycogenolytic capacities and that ven- } \\
\text { tricular wall stretch represents an early and major determinant of } \\
\text { the } \mathrm{O}_{2} \text { uptake. Moreover, the fact that } \mathrm{O}_{2} \text { and glycogen con- } \\
\text { sumptions were not affected by inhibition of glyceraldehyde-3- } \\
\text { phosphate dehydrogenase provides indirect evidence for an ac- } \\
\text { tive glycerol-phosphate shuttle in the embryonic cardiomyocytes. } \\
\text { (Pediatr Res 49: 363-372, 2001) }\end{array}$ \\
\hline
\end{tabular}

The embryonic/fetal heart operates and develops normally in a relatively hypoxic microenvironment and shows both aerobic and anaerobic energy-producing capacities. In such a heart, by contrast with the adult, mitochondria convert fatty acids to energy at a very low rate (1), whereas glycolysis contributes significantly to ATP production $(2,3)$ and glycogen turnover is rapid (4). Such metabolic features confer a benefit to the developing heart, because glucose requires less $\mathrm{O}_{2}$ than fatty acids to produce a given amount of ATP, which is advantageous specially when $\mathrm{O}_{2}$ availability is limited $(5,6)$.

The embryonic myocardium (7-9) displays also a glycogen concentration 10-20-fold higher than in the adult (3) and can tolerate a transient depletion of exogenous substrates in normoxia (10) or even recover rapidly from substrate-free anoxic episodes $(11,12)$. Similar characteristics are found in fetal and

Received April 26, 2000; accepted October 26, 2000.

Correspondence and reprint requests: Eric Raddatz, PhD., Institute of Physiology, Faculty of Medicine, University of Lausanne, 7 rue du Bugnon, CH-1005, Lausanne, Switzerland.

Supported in part by the Swiss National Science Foundation Grant 31-37668.93. neonatal hearts (13-15). However, in avian embryos (16) and mammalian fetuses (17), the cardiovascular response to $\mathrm{O}_{2}$ lack is very rapid despite important glycolytic capacities, indicating that under physiologic conditions, the embryonic/ fetal heart works at the upper limit of its function curve. Indeed, during early development, the heart grows rapidly, its hemodynamic performances such as developed pressure and mechanical work increase significantly (18), and its $\mathrm{O}_{2}$ demand increases at the same time (19), making cardiac activity critically dependent on $\mathrm{O}_{2}$. Moreover, because extrinsic cardiac innervation is absent at early stages, regulation of the cardiovascular function is directly dependent on intrinsic mechanisms at the tissue level. For example, alterations of loading conditions of the ventricle affect directly and significantly the cardiovascular performances (20). Such alterations should also induce changes in myocardial energy demand and production, which deserve to be investigated. Given the recent progress in fetal cardiology and the lack of information about mechanoenergetics of the developing heart, the knowledge of the main determinants of the $\mathrm{O}_{2}$ consumption, the ratio of basal to total 
metabolism, and the mechanical efficiency throughout early cardiogenesis is of importance. In particular, the spatiotemporal pattern of metabolic activity remains to be characterized.

Glucose catabolism along two distinct pathways (glycolysis and mitochondrial oxidation) is essential to ensure normal cardiac morphogenesis and function. In the embryonic chick heart (21-23) and in the fetal mammal heart (2, 3, 24), lactic production and the pentose-phosphate pathway are especially active and appear to be primarily dependent on exogenous glucose rather than on glycogen. Whether glucose derived from glycogen is preferentially oxidized in comparison with exogenous glucose, as it is in adult cardiomyocytes (25), has to be explored.

The present study was undertaken 1) to determine the relative contribution of the aerobic and glycolytic pathways to energy production during early cardiogenesis, 2) to find out whether atrium, ventricle, and conotruncus show differences of oxidative and/or glycogenolytic capacities, and 3) to investigate the effects of mechanical loading and beating rate on energy metabolism of the embryonic myocardium.

Preliminary results of this study have appeared as abstracts $(11,26)$.

\section{METHODS}

\section{Chemicals and Media}

$\mathrm{d}(+)$ Glucose and l-epinephrine were purchased from Fluka, IAA and 2,3-diphosphoglycerate from Sigma Chemical Co., DNP from Serva, and verapamil from Knoll AG Germany (Isoptin).

The standard culture medium was composed of (in mmol/L): $\mathrm{NaCl}$ 99.25; KCl 2.01; $\mathrm{Na}_{2} \mathrm{HPO}_{4} \cdot 2 \mathrm{H}_{2} \mathrm{O} 10.67 ; \mathrm{KH}_{2} \mathrm{PO}_{4} 2.65$; $\mathrm{MgCl}_{2} \cdot 6 \mathrm{H}_{2} \mathrm{O} 0.79 ; \mathrm{CaCl}_{2} \cdot 2 \mathrm{H}_{2} \mathrm{O} \quad 0.75 ; \mathrm{d}(+)$ glucose $8.0 ; \mathrm{pH}$ measured $7.35 ; 235 \mathrm{mosmol} / \mathrm{kg} \mathrm{H} \mathrm{H}_{2} \mathrm{O}$. Buffering capacity, 6.93 $\mu \mathrm{mol} \mathrm{H} \mathrm{H}^{+} /(\mathrm{mL} \cdot \Delta \mathrm{pH}=1)$.

The $\mathrm{O}_{2}$ source was purified human $\mathrm{Hb}$ diluted at a final monomeric concentration of $1 \mathrm{mmol} / \mathrm{L}$ in phosphate buffer (Sørensen) at pH 6.8 and in the presence of $0.5 \mathrm{mmol} / \mathrm{L}$ 2,3-diphosphoglycerate to decrease affinity for $\mathrm{O}_{2}$ (19). This solution was equilibrated with a gas mixture of $8 \% \mathrm{O}_{2}$ and $92 \%$ $\mathrm{N}_{2}$ to maintain $\mathrm{Hb}$ at approximately $50 \%$ saturation.

\section{Dissection of Embryos and Mounting of Isolated Hearts}

Fertilized eggs from Warren hens were incubated 40, 72, and $96 \mathrm{~h}$ at $38^{\circ} \mathrm{C}$ and $90 \%$ relative humidity to obtain embryos at stages 11 (heart rudiments fused), 20 (S-shaped heart), and 24HH (septating trabeculated heart) according to Hamburger and Hamilton (27), respectively. Entire hearts were carefully excised from explanted embryos by section at the level of the ventral aorta and the sinus venosus at stage $11 \mathrm{HH}$ and at the level of the truncus arteriosus as well as between the sinus venosus and the atrium at stage 20 and $24 \mathrm{HH}$. In a set of experiments, isolated hearts were divided into atria (left + right), ventricle, and conotruncus, the cutting being performed at the level of the atrioventricular canal and at the level of the ventriculoconal junction.
As described elsewhere (19), the isolated spontaneously beating heart was placed in the culture compartment $(40 \mu \mathrm{L})$ of an airtight stainless steel chamber provided with two glass windows for observation and measurements and maintained under strictly controlled metabolic conditions on the stage of an inverted microscope (IMT-2 Olympus, Tokyo, Japan) equipped with a thermostabilized incubator at $37.5^{\circ} \mathrm{C}$. The culture compartment was separated from the $\mathrm{O}_{2}$ source compartment (12 $\mu \mathrm{L}, 0.7-\mathrm{mm}$ thick) by a thin $(15 \mu \mathrm{m})$ transparent and gas-permeable silicone membrane (RTV141, RhônePoulenc, Lyon, France). The compartment of the $\mathrm{O}_{2}$ source (oxyhemoglobin) was perfused at a standard rate of $56 \mu \mathrm{L} / \mathrm{min}$, and the composition of the culture medium could be modified using remote-controlled push-pull syringes.

\section{Measurement of Regional $\mathrm{O}_{2}$ Consumption}

The regional $\mathrm{O}_{2}$ uptake was measured according to the spectrophotometric technique previously published (19) with few modifications. Briefly, the principle of the method was to use oxyhemoglobin as the $\mathrm{O}_{2}$ donor as well as the indicator of respiration. In stop-flow condition, the $\mathrm{O}_{2}$ uptake of the tissue was proportional to the rate of desaturation of oxyhemoglobin measured photometrically $(\Delta \mathrm{OD} / \Delta \mathrm{t})$. The light source $(442$ $\mathrm{nm}$ ) was the beam of a helium cadmium laser (Liconix, U.S.A.) controlled and stabilized using an acoustico-optic modulator. The measuring beam was focalized on and passed through a selected region (50 $\mu \mathrm{m}$ in diameter) of the slightly flattened and rather transparent embryonic heart. The output signal from the phototransistor of the photometer attached to the trinocular of the microscope was A/D converted, recorded, and processed using an Apple Macintosh.

The heart was allowed to equilibrate in the chamber for 30-40 min before the first measurement. Then, $\mathrm{O}_{2}$ consumption was determined alternately at the level of atrium, ventricle, and conotruncus. Recordings of the transmural $\mathrm{O}_{2}$ flux expressed as nmol $\mathrm{O}_{2} /\left(\mathrm{h} \cdot \mathrm{mm}^{2}\right)$ in a given region were performed during short periods of stop-flow (30 s) and systematically duplicated at 1-min intervals. The reproducibility of these measurements was fully satisfactory with a coefficient of variation of $2 \% . \mathrm{O}_{2}$ consumption was corrected for protein content to obtain the oxidative capacity expressed as $\mathrm{nmol} \mathrm{O}_{2} /(\mathrm{h} \cdot \mu \mathrm{g})$. Renewal of the culture medium or changing $\mathrm{O}_{2}$ delivery by varying the rate of $\mathrm{Hb}$ perfusion within the range of $28-112$ $\mu \mathrm{L} / \mathrm{min}$ did not alter $\mathrm{O}_{2}$ uptake.

\section{Determination of Glycogen Content, Glycogenolysis, and Lactate Production}

Glycogen content was determined spectrofluorometrically (28) using an automated setup and expressed as GU.

Before dissection and storage at $-20^{\circ} \mathrm{C}$, all the excised hearts were thoroughly rinsed at $0-4^{\circ} \mathrm{C}(60 \mathrm{~min}$ on a rotary shaker) in glucose-free solution to remove extracellular glucose remaining in cardiac cavities that could interfere with ulterior measurements. Washing hearts under these conditions had no effect on glycogen content. Atria, ventricles, and conotruncus were pooled at stage 20 (20 hearts) and 24HH (10 hearts). Glycogen and protein in the different cardiac regions 
were determined in the same pools. For determination of the total protein and glycogen content, 4, 2, and 1 entire hearts were used at stage 11,20 , and $24 \mathrm{HH}$, respectively. After thawing, all the samples were sonicated $(3 \times 2 \mathrm{~s}$ on an ice bath) for biochemical determinations.

For determination of glycogenolysis, isolated hearts were dissected either immediately after removal from the embryos or after $2 \mathrm{~h}$ of incubation in normoxic glucose-free medium at $37.5^{\circ} \mathrm{C}$. Glycogenolytic rate was obtained as the difference between glycogen content determined before and after incubation. It was tested that glycogen content decreased linearly with respect to time, indicating that the rate of glycogenolysis was constant throughout this experiment.

The lactate produced by the hearts in the culture medium within $2 \mathrm{~h}$ was measured spectrophotometrically according to Rosenberg and Rush (29).

The aerobic and glycolytic production of ATP was calculated on the stoichiometric basis of 6 ATP generated per molecule of $\mathrm{O}_{2}$ consumed (aerobic) and 1 ATP generated per molecule of lactate produced (glycolytic).

\section{Morphometry}

The end-diastolic external wall area of atrium, ventricle, and conotruncus, the ventricular perimeter, and shortening at the apex of the ventricle were obtained from frames of video recordings of contracting hearts performed before and after each series of measurements. The end-diastolic and endsystolic external perimeters of the ventricle were calculated from the distance between the middle of the inner curvature (localized between atrioventricular cushions and conotruncal ridges) and the apex. Because the hearts were slightly flattened by the silicone membrane, the morphometric analysis, based on video recordings, was performed on the assumption that the preparation could be considered as rather two-dimensional.

\section{Experiments}

Effects of oxidizable exogenous substrates on myocardial $\mathrm{O}_{2}$ uptake. $\mathrm{O}_{2}$ consumption of the whole heart and in each cardiac region was determined in the absence and presence of exogenous glucose $\left(8 \mathrm{mmol} / \mathrm{L}\right.$, control). The $\mathrm{O}_{2}$ uptake of the empty contracting heart (no pressure generated) corresponded to basal $\mathrm{O}_{2}$ consumption plus suprabasal $\mathrm{O}_{2}$ requirement for mechanical deformation (measurable shortening due to crossbridge cycling) and ionic activation.

Basal oxidative metabolism of the loaded hearts. The basal oxidative metabolism of the nonbeating loaded embryonic heart includes aerobic energy cost of proliferation, differentiation, maturation, and maintenance of ionic gradients and cellular integrity. To determine the corresponding basal $\mathrm{O}_{2}$ consumption, electromechanical work (ionic activation + cross-bridge cycling) was minimized by maintaining the hearts in diastolic arrest by use of the calcium antagonist verapamil at a final concentration of $1 \mu \mathrm{M}(30)$.

Effects of beating rate and mechanical loading on myocardial $\mathrm{O}_{2}$ uptake. To investigate whether myocardial $\mathrm{O}_{2}$ consumption was related to beating rate, epinephrine $(11 \mu \mathrm{M})$ was added to accelerate HR. The relationship between ventricular
$\mathrm{O}_{2}$ uptake and $\mathrm{HR}$ was determined only at stage $24 \mathrm{HH}$, as catecholamines have significant positive chronotropic (31) and inotropic (32) effects from this stage onward. The consequences of exposure to verapamil or epinephrine on enzymatic activities, glucose transport, and glycogenolysis were not investigated in the present study.

In a set of separate experiments to mimic loaded conditions at stage 20 and $24 \mathrm{HH}$, the ventricle of isolated hearts was filled with viscous deformable biocompatible and transparent silicone oil (Silbione V1000, Rhône-Poulenc, Lyon, France) according to our previous study (33). To adjust the load for different heart sizes, oil was gently introduced using a glass micropipette under visual control until diastolic and systolic diameters of the ventricle reached physiologic values determined in ovo (34). The drop of silicone, ovoid in shape, was squeezed at each ventricular contraction, partially bulged into atrioventricular and predominantly ventriculoconal canals, and then returned to its initial shape during diastole. Such reversible geometric modifications show that the volume of the ventricle varied according to cardiac cycle and that pressure was generated, because the radii of curvature at the extremities of the drop were shorter during systole (Laplace law).

The coefficient of $\mathrm{O}_{2}$ solubility in this silicone oil is much higher than in the culture medium, i.e. 8.29 versus $0.982 \mathrm{nmol}$ $\mathrm{O}_{2} /(\mu \mathrm{L} \cdot 760 \mathrm{~mm} \mathrm{Hg})$ at $37^{\circ} \mathrm{C}$. For this reason, in contrast with unloaded conditions, a correction factor of 1.11 was used to calculate the actual $\mathrm{O}_{2}$ consumption of loaded ventricles.

The metabolic and functional changes after addition of glucose, drugs, and inhibitors were followed during a period of at least $40 \mathrm{~min}$. All the solutions were adjusted to $\mathrm{pH} 7.35$. Protein content was determined according to Lowry et al. (35) using bovine serum albumin as standard.

An index of mechanical activity of the ventricle per unit of time was calculated as follows: [perimeter shortening $(\mathrm{mm}) /$ end-diastolic perimeter $(\mathrm{mm})$ ] [ [end-diastolic wall area $\left(\mathrm{mm}^{2}\right)$ ] (beats/min). This index reflects the total movement of myocardial wall per minute $\left(\mathrm{mm}^{2} / \mathrm{min}\right)$.

Inhibition and stimulation of glycolysis and mitochondria. Glycolysis was blocked at the level of the G3PDH by using IAA $(100 \mu \mathrm{M})$. The maximal oxidative capacity was assessed by activating specifically and maximally the mitochondrial electron transport chain with uncoupling agent DNP $(200 \mu \mathrm{M})$.

\section{Normalization and Statistics}

Unless otherwise stated, $\mathrm{O}_{2}$ uptake, lactate production, and glycogenolysis were corrected for the mean protein content of the distinct cardiac regions and of the whole heart.

Values are given as mean \pm SEM. Statistical analysis was performed using 1-way ANOVA, Tukey-Kramer, and unpaired or paired $t$ test. Statistical significance was defined by a value of $p \leq 0.05$.

The present study conforms with the Guide for the Care and Use of Laboratory Animals published by the U.S. National Institutes of Health. 


\section{RESULTS}

\section{Biochemical, Morphometric, and Functional Parameters of the Isolated Heart}

Myocardial wall area, protein content, and glycogen store are reported in Table 1. The protein content of the whole heart increased approximately 22 -fold, whereas the end-diastolic area increased by 8 -fold between stage 11 and $24 \mathrm{HH}$ (i.e. within $56 \mathrm{~h}$ ), reflecting essentially the rapid thickening of the growing myocardial wall. The protein/area ratio increased in all the regions and corresponded to the quantity of protein constituting the myocardial wall under $1 \mathrm{~mm}^{2}$ of external surface. Moreover, this ratio was useful to take into consideration the thinning of the ventricular wall when it was stretched by mechanical loading.

Throughout development, normalized glycogen remained rather stable in atrium and ventricle but decreased markedly in conotruncus and was much higher in atrium than in conotruncus at stage $24 \mathrm{HH}$ (Table 2). Under our experimental conditions, the end-diastolic perimeter and perimeter shortening of the unloaded ventricle as well as HR increased significantly from stage 11 to $24 \mathrm{HH}$ (Table 3 ).

The index of mechanical activity was $2.8,7.5$, and 11.9 $\mathrm{mm}^{2} / \mathrm{min}$ in unloaded hearts at stage 11,20 , and $24 \mathrm{HH}$, and 15.5 and $22.4 \mathrm{~mm}^{2} / \mathrm{min}$ in loaded hearts at stage 20 and $24 \mathrm{HH}$, respectively.

\section{Metabolic Characteristics within the Developing Heart}

The transmural $\mathrm{O}_{2}$ flux measured along the heart tube ranged from 0.6 to 1.0 at stage $11 \mathrm{HH}$ and from 1.5 to $2.1 \mathrm{nmol}$ $\mathrm{O}_{2} /\left(\mathrm{h} \cdot \mathrm{mm}^{2}\right)$ at stage $20-24 \mathrm{HH}$. The corresponding unloaded oxidative metabolism ranged from 0.2 to $0.5 \mathrm{nmol} \mathrm{O}_{2} /(\mathrm{h} \cdot \mu \mathrm{g}$ protein), did not depend on exogenous glucose, and was the highest in atria (Table 4).

Reserves of oxidative capacity assessed by mitochondrial uncoupling were important in the youngest hearts and in conotruncus (Fig. 1). Values of $\mathrm{O}_{2}$ uptake determined 3 to 6 min after addition of DNP could be lower than the actual peak of $\mathrm{O}_{2}$ uptake reached just before the first measurement. Indeed, at stage 20 and $24 \mathrm{HH}$, the fall in $\mathrm{O}_{2}$ uptake during the first 30 min of exposure to DNP could be fitted using an exponential curve with a correlation coefficient $\left(r^{2}\right)$ ranging from 0.90 to 0.99 (Fig. 1a). Thus, the extrapolated values of ventricular transmural $\mathrm{O}_{2}$ flux at the very beginning of exposure to DNP were $2.8 \pm 0.15(n=3)$ and $2.4 \pm 0.2(n=3) \mathrm{nmol}$ $\mathrm{O}_{2} /\left(\mathrm{h} \cdot \mathrm{mm}^{2}\right)$ at stage 20 and $24 \mathrm{HH}$, respectively, and were $10 \%$ higher than the values determined experimentally. These extrapolated values correspond to an oxidative capacity of 0.53 and $0.24 \mathrm{nmol} \mathrm{O}_{2} /(\mathrm{h} \cdot \mu \mathrm{g})$ at stage 20 and $24 \mathrm{HH}$, respectively, and most likely represent the lowest limits of the actual peak values. Mitochondrial uncoupling initially accelerated the hearts and then resulted in cessation of contractions within 18 $\pm 5(n=3)$ and $19 \pm 1(n=3)$ min at stage 20 and $24 \mathrm{HH}$, respectively, but surprisingly did not affect contractions of the younger stage (stage 11HH) (Fig. 1a).

From stage 11 to stage $24 \mathrm{HH}$, glycogenolysis provided glucose at a rate greatly sufficient to maintain cellular oxidations, IAA-inhibitable lactate production (Table 5), and contractile activity for hours in substrate-free medium (assuming that $6 \mathrm{O}_{2}$ are used to fully oxidize $1 \mathrm{GU}$ and that $2 \mathrm{~mol}$ of lactate are derived from $1 \mathrm{GU})$. The contribution of another endogenous store such as fatty acids to ATP production was not considered, because their rate of oxidation appears to be negligible up to stage 24HH (1).

Normalized glycogenolysis almost tripled in the whole heart between stage 11 and $24 \mathrm{HH}$ but varied regionally, the highest value being found in atria and the lowest in conotruncus (Table 4).

In the unloaded beating hearts, the contribution $(30 \%)$ of glycolytically derived ATP, assessed by lactate production, remained stable throughout early cardiogenesis (Table 5).

\section{Effects of Exogenous Glucose}

Whatever the stage investigated, 1) $\mathrm{O}_{2}$ consumption in atria, ventricle, and conotruncus was independent of exogenous glucose, 2) glucose prevented glycogen degradation, and 3) glucose stimulated aerobic lactate production (Table 5). Ventric-

Table 1. Changes in morphometric and biochemical parameters showing rapid myocardial growth during early embryogenesis

\begin{tabular}{|c|c|c|c|}
\hline & $\begin{array}{c}\text { Wall area } \\
\mathrm{mm}^{2}\end{array}$ & $\begin{array}{c}\text { Protein content } \\
\mu \mathrm{g}\end{array}$ & $\begin{array}{c}\text { Glycogen store } \\
\text { nmol GU }\end{array}$ \\
\hline \multicolumn{4}{|c|}{ Stage $11 \mathrm{HH}$} \\
\hline A & $0.46 \pm 0.02(31)$ & nd & nd \\
\hline $\mathrm{V}$ & $0.44 \pm 0.02(31)$ & nd & nd \\
\hline CT & $0.24 \pm 0.01(31)$ & nd & nd \\
\hline $\mathrm{t}$ & $1.14 \pm 0.04(31)$ & $3.1 \pm 0.5[3]$ & $1.3 \pm 0.1[11]$ \\
\hline \multicolumn{4}{|c|}{ Stage $20 \mathrm{HH}$} \\
\hline A & $1.28 \pm 0.04(33)$ & $5.1 \pm 0.3[8]$ & $3.9 \pm 0.2[4]$ \\
\hline $\mathrm{V}$ & $1.96 \pm 0.05(33)$ & $10.3 \pm 0.5[8]$ & $6.7 \pm 1.1[4]$ \\
\hline $\mathrm{CT}$ & $1.10 \pm 0.04(33)$ & $3.5 \pm 0.3[8]$ & $1.9 \pm 0.4[4]$ \\
\hline $\mathrm{t}$ & $4.34 \pm 0.11(33)$ & $18.6 \pm 0.6[11]$ & $14.3 \pm 0.7[25]$ \\
\hline \multicolumn{4}{|c|}{ Stage $24 \mathrm{HH}$} \\
\hline A & $2.70 \pm 0.09(32)$ & $16.8 \pm 1.5[10]$ & $16.3 \pm 1.7[4]$ \\
\hline $\mathrm{V}$ & $4.34 \pm 0.12(32)$ & $44.3 \pm 2.6[10]$ & $27.8 \pm 4.1[4]$ \\
\hline $\mathrm{CT}$ & $1.92 \pm 0.04(32)$ & $12.8 \pm 1.4[10]$ & $4.3 \pm 0.8[4]$ \\
\hline $\mathrm{t}$ & $8.97 \pm 0.21(32)$ & $68.3 \pm 5.0[13]$ & $63.1 \pm 2.2(53)$ \\
\hline
\end{tabular}

Myocardial end-diastolic wall area $\left(\mathrm{mm}^{2}\right)$, protein content $(\mu \mathrm{g})$, and glycogen store (nmol GU/heart) in atrium $(\mathrm{A})$, ventricle $(\mathrm{V})$, conotruncus $(\mathrm{CT})$, and in the whole heart (t). Mean \pm SEM; ( ), no. of individual hearts; [ ], no. of determinations on pooled hearts; unloaded conditions; nd, not determined. 
Table 2. Regional normalized glycogen content (nmol GU/Mg protein) at stage 20 and $24 H H$

\begin{tabular}{cccc}
\hline & Atrium & Ventricle & Conotruncus \\
\hline Stage 20HH & $0.74 \pm 0.03$ & $0.70 \pm 0.03$ & $0.60 \pm 0.03$ \\
Stage 24HH & $0.91 \pm 0.12^{*}$ & $0.59 \pm 0.09$ & $0.32 \pm 0.05 \S$ \\
\hline
\end{tabular}

Both glycogen and protein contents were determined in the very same hearts. Mean \pm SEM. Four determinations for each region. $* p<0.05 v s \mathrm{CT}$ at stage 24HH; $\S p<0.01 v s \mathrm{CT}$ at stage $20 \mathrm{HH}$ (ANOVA).

Table 3. Morphometric and functional parameters of the empty and loaded contracting ventricle

\begin{tabular}{|c|c|c|c|c|c|c|c|}
\hline \multicolumn{2}{|c|}{ Wall area $\mathrm{mm}^{2}$} & \multicolumn{2}{|c|}{ End-diastolic perimeter $\mathrm{mm}$} & \multicolumn{2}{|c|}{ Perimeter shortening $\mu \mathrm{m}$} & \multicolumn{2}{|c|}{ HR beats / min } \\
\hline $11 \mathrm{HH} \quad 0.44 \pm 0.02(31)$ & nd & $0.87 \pm 0.02$ & nd & $67.6 \pm 3.0$ & nd & $83 \pm 4$ & nd \\
\hline $24 \mathrm{HH} 4.399 \pm 0.13(29)$ & $5.54 * q \pm 0.17(24)$ & $3.379 \pm 0.06$ & $3.66^{* q} \pm 0.06$ & $76.29 \pm 5.0$ & $92.3 \pm 6.2$ & $120 \pm 5$ & $160 * \Phi \pm 6$ \\
\hline
\end{tabular}

External wall area, end-diastolic perimeter, perimeter shortening, and HR were measured after stabilization in the culture chamber. Values obtained with and without glucose were pooled because they were not significantly different. (), no. of hearts investigated; mean \pm SEM; $* v$ unloaded ( $p \leq 0.03$ ); $§ s$ stage $11 \mathrm{HH}$ $(p<0.05)$; $\lceil v s$ stage 20HH $(p \leq 0.004)$; unpaired $t$ test.

Table 4. Oxidative (ox; nmol $\mathrm{O}_{2} \cdot h^{-1} \cdot \mu \mathrm{g}_{\text {protein }}{ }^{-1}$ ) and glycogenolytic (gg; nmol $\mathrm{GU} \cdot h^{-1} \cdot \mu g_{\text {protein }}{ }^{-1}$ ) capacities in atrium, ventricle, conotruncus, and in whole hearts

\begin{tabular}{|c|c|c|c|c|c|c|c|c|}
\hline \multirow[b]{2}{*}{ stage } & \multicolumn{2}{|c|}{ Atrium } & \multicolumn{2}{|c|}{ Ventricle } & \multicolumn{2}{|c|}{ Conotruncus } & \multicolumn{2}{|c|}{ Whole heart } \\
\hline & ox & gg & ox & gg & ox & gg & ox & gg \\
\hline $11 \mathrm{HH}$ & nd & nd & nd & nd & nd & nd & $0.30 \pm 0.02$ & 0.10 \\
\hline $24 \mathrm{HH}$ & $0.29 * \dagger \pm 0.01$ & 0.22 & $0.19 \pm 0.01$ & 0.17 & $0.25^{*} \pm 0.01$ & 0.04 & $0.24 \pm 0.01$ & 0.26 \\
\hline
\end{tabular}

At each stage, values of ox were obtained from 31-33 unloaded hearts. All values of gg were obtained from four determinations (see 'Material and Methods'). Mean \pm SEM. * $v s$ ventricle; $\uparrow v s$ conotruncus; $\S v s$ stage 11 or $24 \mathrm{HH}$ (ANOVA).

ular end-diastolic perimeter and shortening and HR were also independent of exogenous substrate. At stage $24 \mathrm{HH}$, HR was $120 \pm 7(n=19)$ and $136 \pm 10(n=14)$ beats/min in the absence and presence of glucose, respectively.

\section{Effects of Loading and HR on Myocardial Metabolism}

Mechanical loading 1) augmented ventricular end-diastolic perimeter (Table 3), 2) accelerated HR by $30 \%$ at stage $24 \mathrm{HH}$ only (Table 3), and 3) increased $\mathrm{O}_{2}$ uptake and shortening at stage 20 and $24 \mathrm{HH}$ (Fig. $2 a$ ). At stage $24 \mathrm{HH}$, additional work due to loading altered neither glycogen remaining in ventricle after $2 \mathrm{~h}$ of activity in glucose-free medium $[15.0 \pm 0.8(n=$ 13 ; loaded $)$ versus $16.5 \pm 1.3(n=12$; unloaded $) \mathrm{nmol}$ $\mathrm{GU} / \mathrm{ventricle}]$ nor lactate production of the whole heart [11.6 $\pm 1.6(n=11$; loaded $)$ versus $11.6 \pm 0.9(n=9$; unloaded $)$ nmol lactate $\cdot h^{-1} \cdot$ heart $\left.^{-1}\right]$.

A linear relationship was found at stage $24 \mathrm{HH}$ between $\mathrm{O}_{2}$ uptake of the loaded ventricle and HR in the absence (Fig. 2b) but not in the presence of glucose (large dispersion of data points, not shown) with $r^{2}$ of 0.67 and 0.12 , respectively. This relationship reflects the actual dependency of mechanical activity on oxidative metabolism, because some data points reported in Figure $2 b$ were obtained from hearts beating spontaneously at low ( 75 beats $/ \mathrm{min}$ ) or high (up to 200 beats $/ \mathrm{min}$ ) rate without any pharmacologic interventions. Addition of epinephrine accelerated the loaded heart from $140 \pm 6$ to 180 \pm 10 beats $/ \mathrm{min}$, increased the ventricular oxidative metabolism from $0.32 \pm 0.02$ to $0.36 \pm 0.01 \mathrm{nmol} \mathrm{O} /(\mathrm{h} \cdot \mu \mathrm{g})(n=3$; $p<0.04)$ but had no significant effect on ventricular enddiastolic perimeter, shortening, and wall area.
The basal $\mathrm{O}_{2}$ uptake of the nonbeating loaded ventricle was $0.23 \pm 0.02(n=3) \mathrm{nmol} \mathrm{O}_{2} /(\mathrm{h} \cdot \mu \mathrm{g}$ protein $)$ and did not depend on exogenous glucose.

\section{Inhibition of G3PDH}

Whatever the stage investigated and glucose concentration, $\mathrm{O}_{2}$ uptake was not modified by blockade of glycolysis during at least 40 min (Fig. 3 and Table 5). However, in nine hearts out of $16, \mathrm{O}_{2}$ decreased by approximately $30 \%$ after $80 \mathrm{~min}$ of exposure to IAA, whereas it was stable in the rest. In substratefree medium, all the hearts tested beat regularly for at least 50 min after addition of IAA. By contrast, in the presence of glucose, hearts were stopped by IAA after $25.7 \pm 1.2 \mathrm{~min}(n$ $=3)$ and $14.8 \pm 1.2 \mathrm{~min}(n=4)$ at stage 20 and $24 \mathrm{HH}$, respectively. At stage $11 \mathrm{HH}$, however, neither $\mathrm{O}_{2}$ consumption nor contractions were altered by IAA (Fig. 3). Glycogen content determined after $2 \mathrm{~h}$ of activity in substrate-free medium was not affected by IAA at stages 11 and $20 \mathrm{HH}$ and was only slightly increased at stage $24 \mathrm{HH}$ (Table 5).

\section{DISCUSSION}

\section{Metabolic Conditions In Vitro}

At the investigated stages, the hearts lack vascularization and all the myocardial demands are met by diffusion. Under our in vitro conditions, although epicardium progressively covers the heart from stage 19 to $26 \mathrm{HH}(36,37)$, the cardiac tissue was adequately oxygenated, taking into account that 1 ) $\mathrm{O}_{2}$ consumption was not dependent on the perfusion rate and increased significantly after mitochondrial stimulation, 2) $\mathrm{Po}_{2}$ 
was buffered by $\mathrm{Hb}, 3)$ the silicone membrane had a high permeability to $\mathrm{O}_{2}$ and $\mathrm{CO}_{2}$, and 4) $\mathrm{HR}$ remained constant during stop-flow periods, which is not observed when the hearts become hypoxic $(30,33)$. Accumulation of metabolites during stop-flow had no effect on $\mathrm{O}_{2}$ uptake, because renewal of the culture medium did not alter $\mathrm{O}_{2}$ uptake and buffering capacity was sufficient as discussed elsewhere $(16,19)$. Furthermore, $\mathrm{HR}$ as well as $\mathrm{O}_{2}$ consumption of atria, ventricle, and conotruncus did not vary for at least $2 \mathrm{~h}$ in the presence or
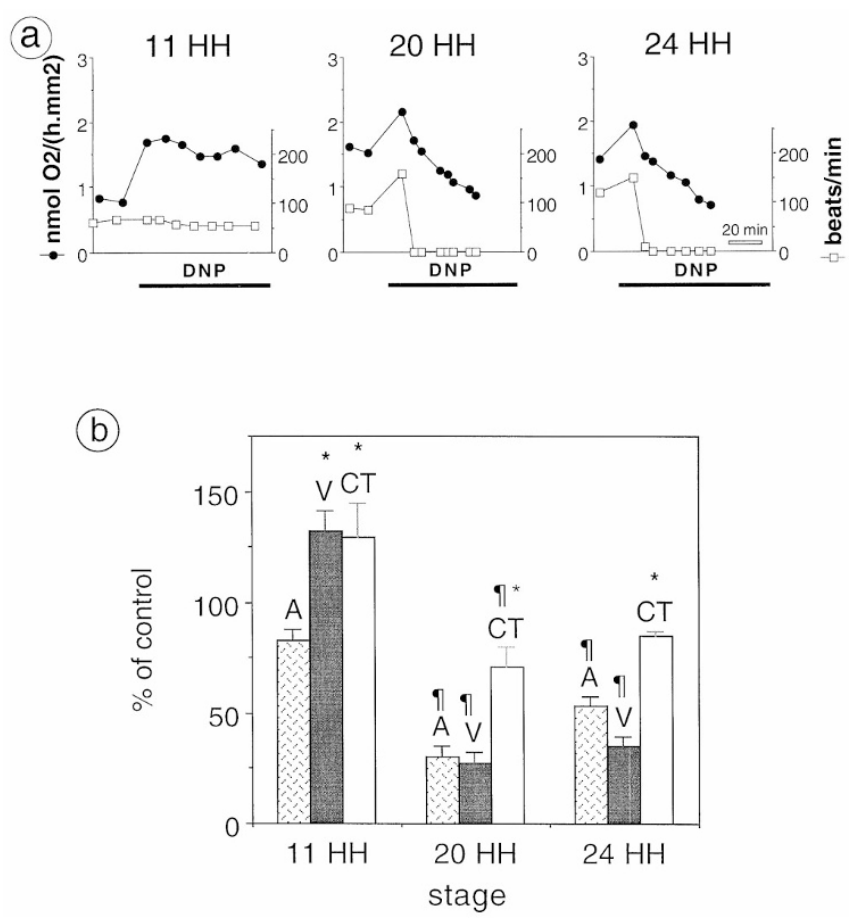

Figure 1. The unloaded embryonic heart displayed high reserves of oxidative capacity. (a) Ventricular transmural $\mathrm{O}_{2}$ flux (left-hand ordinate, closed circles) and beating rate (right-hand ordinate, open squares) before and after mitochondrial uncoupling with DNP in representative experiments. (b) Increase of $\mathrm{O}_{2}$ uptake induced by DNP was expressed as percent of control values. $A$ indicates atrium; $V$, ventricle; $C T$, conotruncus. Values are mean $\pm \mathrm{SEM}$. Three hearts have been investigated at each stage; glucose, $8 \mathrm{mmol} / \mathrm{L} ; \boldsymbol{q}$, vs stage $11 \mathrm{HH}(p<0.05)$; *, vs A or V $(p<0.05)$ (ANOVA). absence of substrate, attesting the remarkable metabolic stability of the hearts contracting spontaneously in the culture chamber.

\section{Regional Differences in Myocardial Oxidative Capacities}

Our results show that oxidative capacity within the embryonic heart was higher in atria, was independent of exogenous glucose, and culminated at stage $20 \mathrm{HH}$. The findings that normalized glycogen content and glycogenolytic rate were the highest in atria clearly indicate that sinoatrial tissue could better tolerate combined $\mathrm{O}_{2} /$ substrates deprivation. This is supported by the observations that sinoatrial spontaneous pacemaking activity can persist under anoxia, whereas ventricle and conotruncus stop $(12,33,38)$. Thus, rhythmic activity of the sinoatrial region could be related to glycogenolytic metabolism, whereas myocardial contractility could depend preferentially on oxidative phosphorylation because mechanical loading increased $\mathrm{O}_{2}$ consumption without modifying glycogenolysis and lactate production. High glycogen concentration has also been reported in the atrium of the 4-12-wk-old human embryonic heart (9).

The lowest glycogenolytic rate and the highest reserve of oxidative capacity were found in conotruncus. This surprising finding could be explained at least partly by the fact that during early cardiogenesis, the primitive myocardial cells of the conotruncus wall differentiate into fibroblast phenotype or smooth muscle (39), which is known to display a high glycolytic metabolism with exogenous glucose as the main substrate (40). It should also be mentioned that conotruncus is a zone in which electromechanical delay and contraction time are the longest (41) and in which extensive programmed cell death (42) could result in mitochondrial dysfunction. Furthermore, expression of the energy-consuming SR $\mathrm{Ca}^{2+}$-ATPase is the lowest in the conotruncal region (43). By contrast, in atrial and ventricular myocardium, cells continue to differentiate into functional aerobic cardiomyocytes and should use optimally their oxidative capacities and glycogen stores to improve their mechanical performances, especially under loaded conditions.

Table 5. Developmental changes in metabolic parameters and effects of blockade of glycolysis in presence or absence of glucose

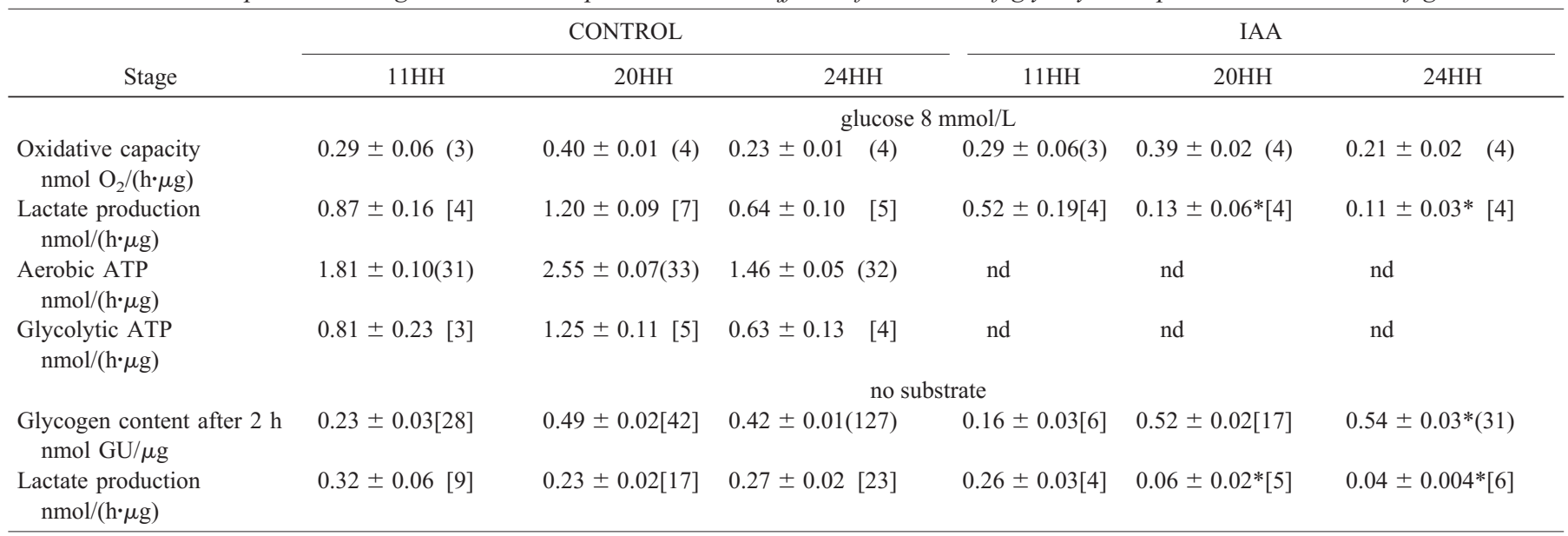

Mean \pm SEM; IAA, $100 \mu \mathrm{M}$; ( ), no. of individual hearts; [ ], no. of determinations on pooled hearts; *vs control $(p<0.003, t$ test). 
(a)

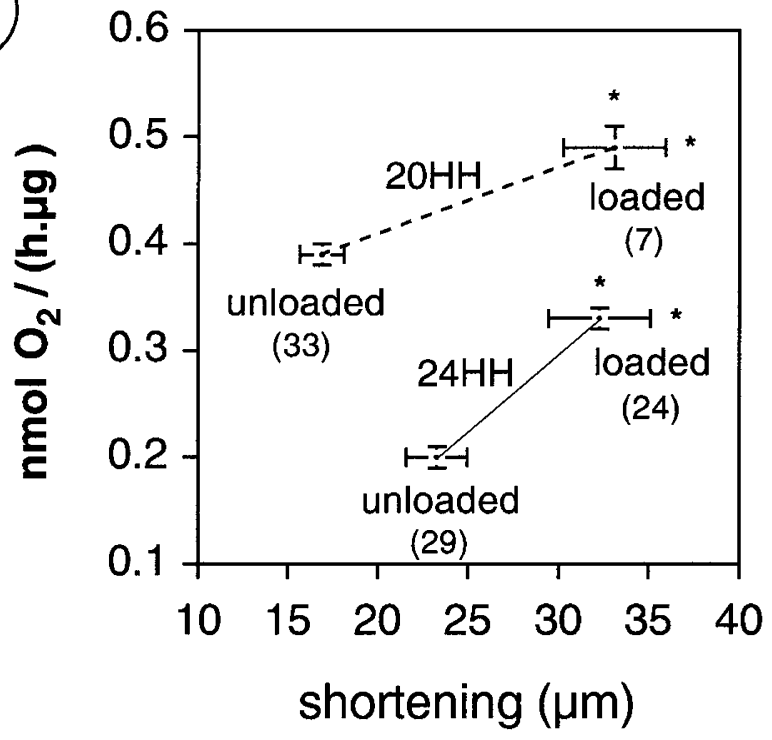

(b)

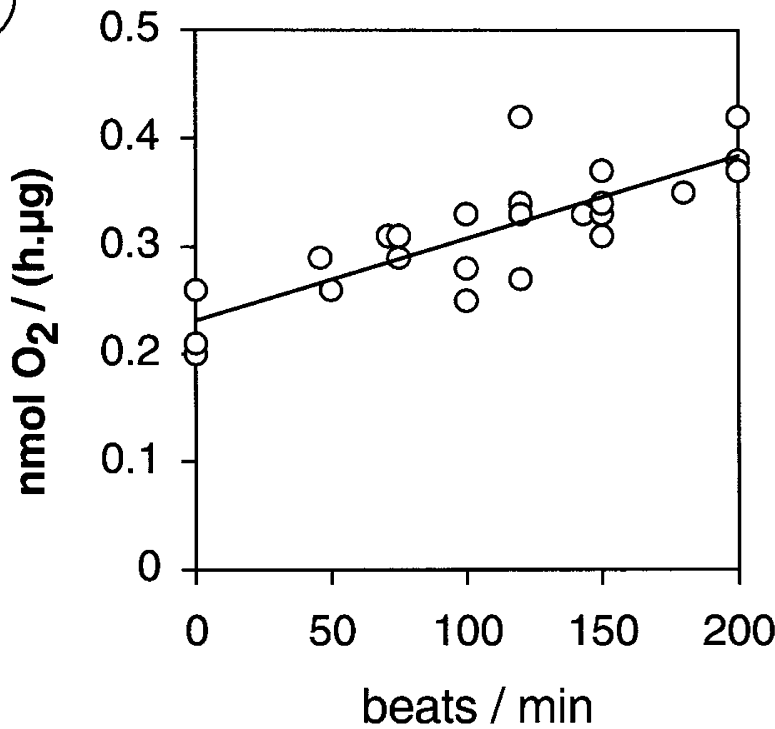

Figure 2. Oxidative capacity of the ventricle was related to wall stretch and HR. (a) Effects of mechanical loading. Ventricular oxidative capacity and shortening varied according to the load (values obtained in absence and presence of glucose were pooled because they were not significantly different). Beating rate of the loaded hearts was $128 \pm 6$ and $160 \pm 6$ at stage 20 and $24 \mathrm{HH}$, respectively. Mean \pm SEM; ( ), number of hearts investigated; *, $p \leq$ $0.006 v s$ unloaded (paired $t$ test). (b) Effects of beating rate. Values of ventricular oxidative capacity $(n=26)$ were determined at stage $24 \mathrm{HH}$ in seven loaded individual hearts deprived of exogenous substrate. Equation of the linear regression is $y=0.001 x+0.232$, with a $r^{2}$ of 0.67 ( $y$ and $x$ are expressed as nmol $\mathrm{O}_{2} /(\mathrm{h} \cdot \mu \mathrm{g})$ and beats/min, respectively). The values obtained at 0,150 , and 200 beats/min were significantly different $(p \leq 0.03)$.

\section{Determinants of the Ventricular $\mathrm{O}_{2}$ Uptake}

At stage $24 \mathrm{HH}$, loading accelerated the heart up to 160 beats/min, which corresponds to the in ovo HR (44), and increased the ventricular oxidative metabolism by $75 \%$. This HR acceleration (30\%) could partly be explained by wall
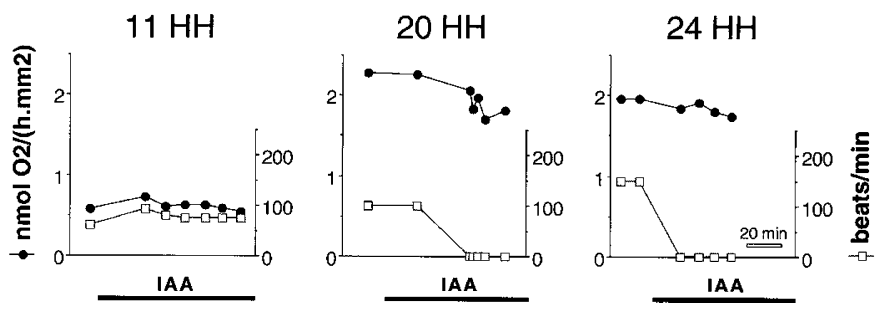

Figure 3. Blockade of glycolysis did not affect myocardial $\mathrm{O}_{2}$ uptake but could prevent contractions. Representative ventricular transmural $\mathrm{O}_{2}$ flux (left-hand ordinate, closed circles) and beating rate (right-hand ordinate, open squares) are reported before and during exposure to IAA $(100 \mu \mathrm{mol} / \mathrm{L})$. Oxidative and contractile activities were dissociated by IAA at stages 20 and $24 \mathrm{HH}$ in contrast with stage $11 \mathrm{HH}$. Glucose, $8 \mathrm{mmol} / \mathrm{L}$; unloaded ventricle.

distension (attested by the increase of wall area and enddiastolic perimeter), resulting in stimulation of stretchactivated ion channels known to be present at this stage (45). According to the relationship in Figure 2b, such an acceleration would increase ventricular $\mathrm{O}_{2}$ uptake by only $13 \%$. Consequently, the specific effect of mechanical loading on oxidative metabolism represented $62 \%$, which is less than in mammalian neonatal ventricle (46). Although changes in volume and developed pressure were not measurable in our experimental conditions, it is reasonable to consider that loading the ventricle increased wall stretch up to physiologic level. This is attested by end-diastolic and end-systolic perimeters (Table 3) comparable to values determined in ovo (34). Whether lengthdependent activation of the sarcomeres occurs in embryonic cardiomyocytes is still unknown. Our data, however, show that myocardial fiber tension is also a major determinant of the $\mathrm{O}_{2}$ consumption in the embryonic heart. Furthermore, at stage $20-24 \mathrm{HH}$, the ventricle contracting in the loaded state appears to use its maximal oxidative capacity, because its transmural $\mathrm{O}_{2}$ flux was comparable to that reached after mitochondrial uncoupling. By comparison, adult heart can use up to $90 \%$ of its maximal oxidative capacity (47).

Loading the ventricle increased the index of mechanical activity by 106 and $88 \%$ and increased concomitantly oxidative metabolism by 25 and $75 \%$ at stages 20 and $24 \mathrm{HH}$, respectively (Fig. 2a). Thus, at stage $24 \mathrm{HH}$, aerobic ATP synthesis seems to be mostly related to mechanical activity as in the adult. By contrast, at stage $20 \mathrm{HH}$, the dissociation between aerobic ATP synthesis and mechanical activity could be partly explained by the fact that the myocardial capacity to produce glycolytic ATP from exogenous glucose is 2-fold higher than at stage $24 \mathrm{HH}$ (Table 5).

The fact that increasing HR augmented $\mathrm{O}_{2}$ uptake only when glucose was lacking (Fig. $2 b$ ) suggests that under physiologic conditions, i.e. working in the presence of glucose, glycolysis rather than mitochondrial oxidations should provide extra energy when the heart accelerates. In the embryonic chick heart, end-systolic pressure increases with HR (48), suggesting that wall stress and energy consumption should increase when the heart accelerates in vivo. Such a relationship between energy expenditure and cardiac frequency is also illustrated in Figure $2 b$. As in our preparation, increasing HR does not alter myocardial suprabasal $\mathrm{O}_{2}$ consumption in isolated immature rabbit heart perfused in the presence of glucose (49). Thus, during the 
embryonic/fetal life, the capability of the working myocardium to use preferentially energy derived from glycolysis could also protect the cardiovascular function against occasional hypoxic stress. Furthermore, utilization of exogenous glucose is energetically more advantageous than endogenous carbohydrate. We have previously shown that oxidizable substrates such as palmitate or pyruvate alter neither glycogenolysis nor $\mathrm{O}_{2}$ consumption of the embryonic heart and that glucose derived from glycogen appears to be the sole substrate used by the embryonic myocardium when glucose is lacking $(11,26)$.

In the loaded heart at stage $24 \mathrm{HH}$, the ratio of basal to total ventricular $\mathrm{O}_{2}$ consumption was rather large (68\%) compared with the ratio of 30 to $50 \%$ found in neonatal (49) and adult hearts $(50-52)$. This could be partly explained by the important energy consumed by biosynthetic activity in the rapidly growing heart. Indeed, the latter passed from 19 to $68 \mu \mathrm{g}$ of protein within $24 \mathrm{~h}$ between stages 20 and $24 \mathrm{HH}$. Reducing equivalents required for these biosyntheses are likely provided by the pentose-phosphate pathway, which is especially active in the rapidly growing avian (21-23) and mammalian (3) hearts.

\section{Developmental Changes in Sensitivity to Metabolic Inhibitors}

At stage $11 \mathrm{HH}$, the remarkable stability of beating rate and amplitude of contraction throughout exposure to metabolic inhibitors (IAA or DNP) could be related to developmental differences in excitation-contraction coupling $(43,53)$ in tolerance to acidosis $(54,55)$ or in utilization of a preexisting pool of intracellular ATP (19). By contrast, at stage $20-24 \mathrm{HH}$, the IAA-induced dissociation between $\mathrm{O}_{2}$ consumption and contractile activity was rapidly achieved only in the presence of glucose. This effect of glucose could result from deleterious upstream accumulation of phosphorylated glycolytic intermediates. Indeed, the latter are known to alter SR calcium release through ryanodine receptors (56) that appear to be functional at these stages $(30,43)$. Inhibition of glycolysis by IAA is also known to suppress spontaneous beating and contractile activities more rapidly in fetal than in adult heart (57).

It is generally accepted that the rapid respiratory rate of mitochondria in the active state (state 3 ) can increase further by approximately $50 \%$ in the presence of a specific uncoupling agent such as DNP, although ATP synthesis is no longer coupled to respiration. Thus, at stage $11 \mathrm{HH}$, myocardial mitochondria appeared to be less active because the DNP-induced stimulation of respiration is higher than at stage $20-24 \mathrm{HH}$, i.e. 80 to $130 \%$ versus 25 to $80 \%$ (Fig. 1). Furthermore, the conotruncus systematically displayed the highest DNP-induced stimulation of $\mathrm{O}_{2}$ uptake whatever the stage. At stage 20$24 \mathrm{HH}$, the biphasic change in HR induced by DNP (Fig. 1) should not affect the biphasic change in $\mathrm{O}_{2}$ uptake because there was no correlation between $\mathrm{HR}$ and $\mathrm{O}_{2}$ uptake under the experimental conditions, i.e. in the presence of glucose.

Regarding the dissociation between $\mathrm{O}_{2}$ uptake and contractile activity induced by DNP, it is difficult to interpret our results apart from the facts that ATP could be rapidly depleted and/or that DNP could hyperpolarize the membrane and suppress action potentials, possibly through activation of ATP- sensitive channels that play a major role in cellular excitability during early cardiogenesis (58). Maximalization of mitochondrial respiration also enhances generation of reactive $\mathrm{O}_{2}$ species (59) that could hasten contractile dysfunction.

\section{Metabolic Pathways in the Embryonic Myocardium}

Inhibition of G3PDH by IAA almost totally suppressed lactate production but altered neither $\mathrm{O}_{2}$ consumption nor glycogenolytic rate. These surprising findings provide indirect evidence that another pathway than glycolysis is involved in $\mathrm{O}_{2}$ consumption and glycogen utilization. Indeed, when G3PDH is inhibited, dihydroxyacetone-phosphate could accumulate upstream and represent a substrate for the glycerolphosphate shuttle pathway. The latter may contribute to transport of reducing equivalents into mitochondria of the embryonic chick myocardium as it does in neonatal mammalian heart (60) and compensate for the low activity of the Krebs cycle and malate-aspartate shuttle (2). Such a concept is also supported by the fact that at stage $24 \mathrm{HH}$, the theoretical $\mathrm{O}_{2}$ uptake dependent on the glycerol-phosphate shuttle corresponds to the actual value of $0.25 \mathrm{nmol} \mathrm{O}_{2} /(\mathrm{h} \cdot \mu \mathrm{g}$ ) (assuming that glucose derived from glycogen is entirely transformed into dihydroxyacetone-phosphate and that 1 atom of oxygen is consumed per mole of reducing equivalent transported via the glycerol-phosphate shuttle).

Our findings indicate also that mechanical activity is dependent on aerobic metabolism early during cardiogenesis but can be temporarily sustained by glycolytic ATP synthesis. Indeed, inhibition of the respiratory chain $(61,19)$ and mitochondrial uncoupling (this study) suppress contractions of myocytes in 2to 10-d-old embryonic chick hearts after a delay of $10-30 \mathrm{~min}$ even in the presence of glucose. Nevertheless, oxidative capacity and normalized lactate production varied in parallel and both culminated at stage $20 \mathrm{HH}$ (Table 5), suggesting that cellular oxidations and glycolytic activity are tightly coupled when glucose is present. Indeed, in the embryonic chick heart, we found that about $30 \%$ of the total ATP could be derived from aerobic lactate production whatever the stage investigated. This proportion is close to the value of $22 \%$ found in fetal guinea pig heart (2) but much higher than in the adult heart, i.e. $5 \%$ (62). This feature could explain the fact that in embryonic cardiomyocytes, ATP concentration can remain unaffected by rather low $\mathrm{Po}_{2}$ (63).

\section{Mechanical Efficiency of the Embryonic Heart}

Between stage 11 and $24 \mathrm{HH}$, the peristaltic-contracting heart tube is transformed into contracting compartments, the geometry of which changes dramatically. Our data show that in loaded hearts, the total energy expenditure (aerobic + glycolytic) per beat decreased from 0.6 to 0.3 pmol ATP. beat $^{-1} \cdot \mu \mathrm{g}_{\text {protein }}{ }^{-1}$, whereas the index of mechanical activity increased by approximately $50 \%$ between stage 20 and $24 \mathrm{HH}$, and, besides, cardiac work is known to increase markedly from stage $24 \mathrm{HH}$ onward (18). Consequently, as suggested in our previous article (19), the mechanical (contractile) efficiency of the cardiac pump does increase with development and could be correlated with maturation of mitochondrial machinery, tran- 
sition from random arrangement of myofibrils to organized sarcomeres, increased density of myofilaments (64), and changes in types of contractile proteins (65). Furthermore, changes in organization of the myofibrillar system, as those described in the young developing heart (64), are thought to control the activity of glycolytic enzymes associated with actin (66). It has also been shown in chick embryo cardiomyocytes that glycolytic enzymes (e.g. aldolase and G3PDH) are associated with actin filaments (66), suggesting that ATP necessary to assure rapid cross-bridge cycling may be provided preferentially by glycolytic activity associated with myofibrils. Such a metabolic microcompartmentation, also proposed in neonatal ventricular myocytes (67), could contribute to improve efficiency.

In conclusion, this study has established for the first time the topography of both the oxidative and glycogen metabolism in the developing chick heart in the unloaded and loaded state. It emerges from our results that the efficiency of the myocardium to use its oxidative and glycogenolytic capacities is the highest in atrium and that ventricular wall stretch represents an early determinant of the myocardial $\mathrm{O}_{2}$ uptake. Our results also provide indirect evidence for an active glycerol-phosphate shuttle involved in the transport of reducing equivalents into mitochondria of the embryonic myocardium.

Acknowledgments. The authors thank Michel Jadé for the construction of the miniaturized culture chamber and Christian Häberli and André Singy for the construction of the electronic hardware.

\section{REFERENCES}

1. Pugh E, Sidbury JB 1971 Fatty acid oxidation in embryonic chick tissues. Biochem et Biophys Acta 239:376-383

2. Jones CT, Rolph TP 1985 Metabolism during fetal life: a functional assessment of metabolic development. Physiol Rev 65:357-430

3. Lopaschuk GD, Collins-Nakai RL, Itoi T 1992 Developmental changes in energy substrate use by the heart. Cardiovasc Res 26:1172-1180

4. Clark CM, Indianapolis MD 1973 Characterization of glucose metabolism in the isolated rat heart during fetal and early neonatal development. Diabetes 22:41-49

5. Baumann R, Meuer HJ 1992 Blood oxygen transport in the early avian embryo. Physiol Rev 72:941-965

6. Rajala GM, Lai CS, Kolesari GL, Cameron RH 1985 ESR measurement of dissolved oxygen in 4-day chick embryo blood. Life Sci 36:291-297

7. Rinaudo MT, Giunta C, Bozzi ML, Bruno R 1968 Enzymes of glycogen synthesis and of glycogenolysis in skeletal muscle, heart, and brain of chicken embryo. Enzymologia 36:321-331

8. Smolich JJ 1995 Ultrastructural and functional features of the developing mammalian heart: a brief overview. Reprod Fertil Dev 7:451-461

9. Tuganowski W, Samek D, Glenc F 1975 Glycogen content in human embryonic heart. In: Roy PE, Harris P (eds) The Cardiac Sarcoplasm. University Park Press, Baltimore, pp 179-180

10. Barry WH, Pober J, Marsh JD, Frankel SR, Smith TW 1980 Effects of graded hypoxia on contraction of cultured chick embryo ventricular cells. Am J Physiol 239:H651H657

11. Raddatz E, Kucera P, Rochat AC, de Ribaupierre Y 1996 Glycogen metabolism in the embryonic heart. J Mol Cell Cardiol 28:A22(abstr)

12. Tran L, Kucera P, de Ribaupierre Y, Rochat AC, Raddatz E 1996 Glucose is arrhythmogenic in the anoxic-reoxygenated embryonic chick heart. Pediatr Res 39:766-773

13. Castaneda AR, Jonas RA, Mayer JE, Hanley FL 1994 Cardiac Surgery of the Neonate and Infant. WB Saunders, Philadelphia, pp 41-53

14. Gelli MG, Enhörning G, Hultman E, Bergström J 1967 Glucose infusion in the pregnant rabbit and its effect on glycogen content and activity of foetal heart under anoxia. Acta Paediatr Scand 57:209-214

15. Young HH, Shimizu T, Nishioka K, Nakanishi T, Jarmakani JM 1983 Effect of hypoxia and reoxygenation on mitochondrial function in neonatal myocardium. Am J Physiol 245:H998-H1006

16. Meiltz A, Kucera P, de Ribaupierre Y, Raddatz E 1998 Inhibition of bicarbonate transport protects embryonic heart against reoxygenation-induced dysfunction. J Mo Cell Cardiol 30:327-335
17. Jensen A, Garnier Y, Berger R 1999 Dynamics of fetal circulatory responses to hypoxia and asphyxia. Eur J Obstet Gynecol 84:155-172

18. Hu N, Clark EB 1989 Hemodynamics of the stage 12 to stage 29 chick embryo. Circ Res 65:1665-1670

19. Raddatz E, Servin M, Kucera P 1992 Oxygen uptake during early cardiogenesis of the chick. Am J Physiol 262:H1224-H1230

20. Keller BB 1997 Embryonic cardiovascular function, coupling, and maturation: a species view. In: Burggren WW, Keller BB (eds) Development of Cardiovascular Systems. Molecules to Organisms. Cambridge University Press, Cambridge, pp $65-87$

21. Coffey RG, Cheldelin VH, Newburgh RW 1964 Glucose utilization by chick embryo heart homogenates. J Gen Physiol 48:105-112

22. Seltzer JL, McDougal Jr DB 1975 Enzyme levels in chick embryo heart and brain from 1 to 21 days of development. Dev Biol 42:95-105

23. Warshaw JB, Rosenthal MD 1972 Changes in glucose oxidation during growth of embryonic heart cells in culture. J Cell Biol 52:283-291

24. Hoerter J 1978 Evolution de la glycolyse myocardique du rat dans la période périnatale. C R Acad Sci 286:465-468

25. Goodwin GW, Ahmad F, Taegtmeyer H 1996 Preferential oxidation of glycogen in isolated working rat heart. J Clin Invest 97:1409-1416

26. Romano R, Kucera P, Rochat AC, de Ribaupierre Y, Raddatz E 1997 Oxidative metabolism in the embryonic heart. J Mol Cell Cardiol 29:A86(abstr)

27. Hamburger V, Hamilton HL 1951 A series of normal stages in the development of the chick embryo. J Morphol 88:49-92

28. Nahorski SR, Rogers KJ 1972 An enzymatic fluorometric micro-method for determination of glycogen. Anal Biochem 49:492-497

29. Rosenberg JC, Rush BF 1966 An enzymatic-spectrophotometric determination of pyruvic and lactic acid in blood. Methodologic aspects. Clin Chem 12:299-307

30. Tenthorey D, de Ribaupierre Y, Kucera P, Raddatz E 1998 Effects of verapamil and ryanodine on activity of the embryonic chick heart during anoxia and reoxygenation. J Cardiovasc Pharmacol 31:195-202

31. Lipshultz S, Shanfeld J, Chacko S 1981 Emergence of beta-adrenergic sensitivity in the developing chicken heart. Proc Natl Acad Sci USA 78:288-292

32. Higgins D, Pappano AJ 1981 Developmental changes in the sensitivity of the chick embryo ventricle to beta-adrenergic agonist during adrenergic innervation. Circ Res 48:245-253

33. Raddatz E, Kucera P, de Ribaupierre Y 1997 Response of the embryonic heart to hypoxia and reoxygenation: an in vitro model. Exp Clin Cardiol 2:128-134

34. Keller BB, Hu N, Clark EB 1990 Correlation of ventricular area, perimeter, and conotruncal diameter with ventricular mass and function in the chick embryo from stages 12 to 24 . Circ Res 66:109-114

35. Lowry OH, Rosebrough NJ, Farr AL, Randall RJ 1951 Protein measurement with the Folin phenol reagent. J Biol Chem 193:265-275

36. Hiruma T, Hirakow R 1989 Epicardial formation in embryonic chick heart: computeraided reconstruction, scanning, and transmission electron microscopic studies. Am J Anat 184:129-138

37. Vrancken Peeters MPFM, Mentink MMT, Poelmann RE, Gittenberger-de Groot AC 1995 Cytokeratins as a marker for epicardial formation in the quail embryo. Anat Embryol 191:503-508

38. Sedmera D, de Ribaupierre Y, Kucera P, Raddatz E 1997 Changes of response to anoxia in developing chick embryonic heart. J Mol Cell Cardiol 29:A45(abstr)

39. Arguello C, de la Cruz MV, Sanchez C 1978 Ultrastructural and experimental evidence of myocardial cell differentiation into connective tissue cells in embryonic chick heart. J Mol Cell Cardiol 10:307-315

40. Paul RJ, Krisanda JM, Lynch RM 1984 Vascular smooth muscle energetics. J Cardiovasc Pharmacol 6:320-327

41. Boucek RJ, Murphy WP, Paff GH 1959 Electrical and mechanical properties of chick embryo heart chambers. Circ Res 7:787-793

42. van den Hoff MJB, van den Eijnde SM, Viragh S, Moorman AFM 2000 Programmed cell death in the developing heart. Cardiovasc Res 45:603-620

43. Moorman AFM, Schumacher CA, De Boer PAJ, Hagoort J, Bezstarosti K, van den Hoff MJB, Wagenaar GTM, Lamers JMJ, Wuytack F, Christoffels VM, Fiolet JWT 2000 Presence of functional sarcoplasmic reticulum in the developing heart and its confinement to chamber myocardium. Dev Biol 223:279-290

44. Akiyama R, Mitsubayashi H, Tazawa H, Burggren WW 1999 Heart rate responses to altered ambient oxygen in early (days 3-9) chick embryos in the intact egg. J Comp Physiol 169:B85-B92

45. Hu Hai, Sachs F 1997 Stretch-activated ion channels in the heart. J Mol Cell Cardiol 29:1511-1523

46. Jessen ME, Abd-Elfattah AS, Wechsler AS 1996 Neonatal myocardial oxygen consumption during ventricular fibrillation, hypothermia, and potassium arrest. Ann Thorac Surg 61:82-87

47. Mootha VK, Arai AE, Balaban RS 1997 Maximum oxidative phosphorylation capacity of the mammalian heart. Am J Physiol 272:H769-H775

48. Casillas CB, Tinney JP, Keller BB 1994 Influence of acute alterations in cycle length on ventricular function in chick embryos. Am J Physiol 267:H905-H911

49. Parrish MD, Farrar S 1990 Force and oxygen consumption in the immature rabbit heart. Pediatr Res 27:476-482

50. Gibbs CL 1995 Mechanical determinants of myocardial oxygen consumption. Clin Exp Pharmacol Physiol 22:1-9

51. Harasawa Y, de Tombe PP, Sheriff DD, Hunter WC 1992 Basal metabolism adds a significant offset to unloaded myocardial oxygen consumption per minute. Circ Res $71: 414-422$

52. Loiselle DS 1987 Cardiac basal and activation metabolism. In: Jacob R, Just Hj, Holubarsch Ch (eds) Cardiac Energetics. Basic Mechanisms and Clinical Implications. Springer Verlag, New York, pp 37-50 
53. Tanaka H, Takagi N, Shigenobu K 1993 Inotropic effects of ryanodine and calcium antagonists on embryonic and hatched chick myocardium. J Dev Physiol 19:235-240

54. Godt RE, Fogaça RTH, Nosek TM 1991 Changes in force and calcium sensitivity in the developing avian heart. Can J Physiol Pharmacol 69:1692-1697

55. Nakanishi T, Okuda H, Nakazawa M, Takao A 1985 Effect of acidosis on contractile function in the newborn rabbit heart. Pediatr Res 19:482-488

56. Kermode H, Chan WM, Williams AJ, Sitsapesan R 1998 Glycolytic pathway intermediates activate cardiac ryanodine receptors. FEBS Lett 431:59-62

57. Su JY, Friedman WF 1973 Comparison of the responses of fetal and adult cardiac muscle to hypoxia. Am J Physiol 224:1249-1253

58. Gryshchenko O, Fischer IR, Dittrich M, Viatchenko-Karpinski S, Soest J, BöhmPinger M, Igelmund P, Fleischmann BK, Hescheler J 1999 Role of ATP-dependent $\mathrm{K}^{+}$channels in the electrical excitability of early embryonic stem cell-derived cardiomyocytes. J Cell Sci 112:2903-2912

59. Ambrosio G, Zweier JL, Duilio C, Kuppusamy P, Santoro G, Elia PP, Tritto I, Cirillo P, Condorelli M, Chiariello M, Flaherty JT 1993 Evidence that mitochondrial respiration is a source of potentially toxic oxygen-free radicals in intact rabbit hearts subjected to ischemia and reflow. J Biol Chem 268:18532-18541
60. Scholz TD, Koppenhafer SL 1995 Reducing equivalent shuttles in developing porcine myocardium: enhanced capacity in the newborn heart. Pediatr Res 38:221-227

61. Doorey AJ, Barry WH 1983 The effects of inhibition of oxidative phosphorylation and glycolysis on contractility and high-energy phosphate content in cultured chick heart cells. Circ Res 53:192-201

62. Liu B, Clanachan AS, Schulz R, Lopaschuk GD 1996 Cardiac efficiency is improved after ischemia by altering both the source and fate of protons. Circ Res 79:940-948

63. Budinger GRS, Chandel N, Shao ZH, Li CQ, Melmed A, Becker LB, Schumacker PT 1996 Cellular energy utilization and supply during hypoxia in embryonic cardiac myocytes. Am J Physiol 270:L44-L53

64. Manasek FJ 1968 Embryonic development of the heart. J Morph 125:329-366

65. Franco D, Lamers WH, Moorman AFM 1998 Patterns of expression in the developing myocardium: towards a morphologically integrated transcriptional model. Cardiovasc Res 38:25-53

66. Minaschek G, Gröschel-Stewart U, Blum S, Bereiter-Hahn J 1992 Microcompartmentation of glycolytic enzymes in cultured cells. Eur J Cell Biol 58:418-428

67. Livingston BE, Altschuld RA, Hohl CM 1996 Metabolic compartmentalization in neonatal swine myocytes. Pediatr Res 40:59-65 